\title{
Editorial
}

\section{E-learning in Psychiatry: How Effective is it?}

In today's era, the busy clinicians often lack time to pore over thick and lengthy books to look for the information they require. For example, while writing a prescription, they have doubts regarding the safety of a psychotropic drugs in a particular medical condition. They are more likely to Google it using their smartphones rather than reach out for a book in their clinics which may or may not contain the information they require. Thus, the biggest advantage of e-learning is accessibility and instant availability. It is very important to get what you want specifically within the shortest possible time. It is also anonymous and accessible to all. However, the information may not always be reliable. The quality and standard of information available at various sites may vary

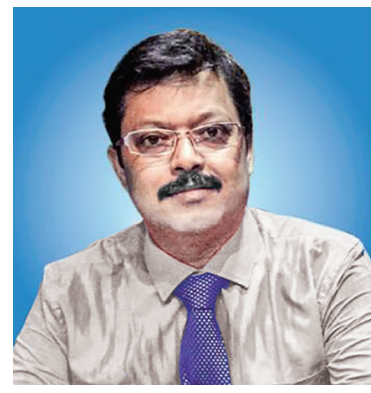
considerably. Also, one has to look carefully to check how long back has the website been updated? DISCERN ${ }^{1}$ is one of the commonly used tools, which is used to assess the quality of information that is available at various websites. One major advantage of learning through the internet is that it can be individualized to suit the clinician's requirement and time. Controlling the content and information inflow is in their hands. Over and above all, animations, graphics and videos can make learning more simple and easy to understand. Once the quality of available information is assessed, learning through the internet becomes far more effective and advantageous than traditional learning methods.

Gautam Saha

Director

Clinic Brain, Neuropsychiatric Institute and Research Center

Barasat, West Bengal, India

E-mail: drgautamsaha@gmail.com

\section{References}

1. Charnock D, Shepperd S, Needham G, et al (1999) DISCERN: an instrument for judging the quality of written consumer health information on treatment choices. Journal of Epidemiology and Community Health, 53: 105-11. 